\title{
SONOGRAPHIC ASSOCIATION OF UTERINE FIBROIDS WITH INFERTILITY AMONG WOMEN OF CHILDBEARING AGE.
}

\author{
1. MID \\ Sonologist Radiology \\ University of Lahore. \\ 2. MID \\ Sonologist Radiology \\ University of Lahore. \\ 3. Ph.D. (Ultrasound) \\ Assistant Professor Radiology \\ University of Lahore. \\ 4. Ph.D. (Ultrasound) \\ Professor Radiology \\ University of Lahore. \\ 5. MID \\ Sonologist Radiology \\ University of Lahore. \\ 6. DMRD \\ Assistant Professor Radiology \\ University of Lahore. \\ 7. M. Phil Biostatistics \\ Lecturer Radiology \\ University of Lahore. \\ 8. M. Phil (Ultrasound) \\ Lecturer Radiology \\ University of Lahore. \\ Correspondence Address: \\ Dr. Sana Amjad \\ Al-Sheikh Jinnah Memorial Welfare \\ Hospital, \\ Near Fort Urdu Bazar Sialkot \\ sanaamjad52@gmail.com \\ Article received on: \\ 14/03/2019 \\ Accepted for publication \\ 25/07/2019
}

\section{INTRODUCTION}

Infertility, is a great social, psycological and economical problem, influencing a large number of individuals all around the world. ${ }^{1}$ It is actually characterized by the failure to give birth to children following more than a year of standard unprotected sexual intercourse. It is classified into primary and secondary infertility ${ }^{2}$ and has proven to be one of the main reasons for women to fall under mental misery due to tremendous pressure and social disgrace. ${ }^{3}$ Accorrding to the worldwide prevelence of infertility in 2010, an expected 48.5 million couples around the world were not able to have a child following five years. Primary infertility rate was found to be $1.9 \%$ among the women aged $20-44$, while secondary nfertility rate was noted to be $10.5 \% .{ }^{4}$ Pakistan on the other hand being one of the most crowded nations of the world, with the population growth

\begin{abstract}
Objectives: To determine sonographic association of uterine fibroids with Diagnostic Centre, Sialkot. Period: From $10^{\text {th }}$ July to $10^{\text {th }}$ October 2018 . Materials \& Methods: The study was started after the approval of ethical committee of the University of Lahore. All the patients were enrolled in this study after signing the informed consent form. Toshiba Xario and Medre transducer frequency ranging from 2 to $6 \mathrm{MHz}$ were used. ultrasound mane A convenient sampling the with the help of Statistical Package for the Social Sciences version 24 (SPSS 24, IBM, Armonk, NY, United States of America). Results: Among 113 subjects, the incidence of uterine fibroid was $32.7 \%$. A significant association ( $p$-value $=0.010$ ) was seen between existence of fibroid of participants had single while $11(9.7 \%)$ of them had multiple fibroids. The location was most commonly seen in anterior and posterior wall, whereas the most common type was found to Sub-Mucosal and Sub-Serosal. Conclusion: Uterine Fibroids were commonly associated with Secondary infertility as compared to primary infertility.
\end{abstract}

Key words: Child Bearing Age, Primary Infertility, Secondary Infertility, Uterine Fibroid, Ultrasound.

Article Citation: Amjad S, Iqbal H, Bacha R, Gilani SA, Uzair M, Malik SS, Fatima M, Farooq SMY. Sonographic association of uterine fibroids with infertility among women of childbearing age. Professional Med J 2020; 27(4):711-716. DOI: 10.29309/TPMJ/2020.27.04.3409

rate of around $2 \%$, has comparitively a higher rate of infertility of about $21.9 \%$ (3.5\% primary and $18.4 \%$ secondary).$^{5}$

Uterine fibroids also known as uterine myomas, is the most commonly occuring (in $20-25 \%$ women) benign tumors of the smooth muscle cells of uterus $^{6,7}$, which is seen to increase with age until fifth decade after which it decreases ${ }^{8}$, and these fibroids are classified on the basis of its location, that is; subserosal fibroids(outside of the uterus), intramural fibroids (within the muscular walls) and submucosal fibroids (in the middle muscle layer of uterus). ${ }^{9}$ Despite the fact that the exact reasons for myomas are not known, progresses have been made in the explaination of the hereditary components (hormones and developmental factors) of these tumors. ${ }^{10}$ On the other hand additional established risk factors for fibroids 
include age, parity, african american heritage and early menarche age. The greater part of women with uterine fibroids are usually asymptomatic, where as only a few have reported symptoms like, irregular prolonged uterine bleeding or spouting, dyspareunia, non-cyclic pelvic pain, miscarriage, bleeding, difficulty conceiving, spontaneous abortion, preterm birth. ${ }^{11,12}$ The sensitivity of USG in the diagnosis of uterine fibroids is $94.5 \%$ while the specificity is $62.5 \%$ and ultrasound accuracy in diagnosing uterine fibroids is $92.0 \% .^{13}$ The hypoechoic pattern of fibroid nodules is the most common. ${ }^{14}$ This present study aims to access the sonographic association of uterine fibroids with infertility among women of childbearing age as female infertility nowadays is a very common social and medical problem, hence this research, therefore intends to determine the possible contribution of uterine fibroids as a predisposing factor of infertility.

\section{MATERIALS \& METHODS}

In this cross-sectional study, data was collected from infertile women of child bearing age visiting different diagnostic setups of Lahore and Sialkot during 4 months, from $10^{\text {th }}$ July to $10^{\text {th }}$ October 2018.

Sample size of 113 patients was calculated by using standardized formula. The study was started after the approval of ethical committee of the University of Lahore. All the patients were enrolled in this study after signing the informed consent form. Data was collected according to the variable of the age, marriage duration, location of fibroids, types of fibroids and size of fibroids. Ultrasound machine Toshiba Xario with convex transducer of frequency range 3 to $6 \mathrm{MHz}$ was used at Gilani Ultrasound Clinic, Lahore and Medison Accuvix V20 with convex transducer of frequency range 2 to $6 \mathrm{MHz}$ was used at Ahsan medical center, Sialkot to evaluate fibroids trans abdominally. All the patients were examined according the American Institute of Ultrasound in Medicine (AIUM) gynecological ultrasound guidelines. ${ }^{15}$ Privacy of the patient was observed all the time and remained of top priority throughout the study.
All the married infertile women (Primary infertile and Secondary infertile) of childbearing age were willingly included.

Any congenital uterine or ovarian anomalies or patients with hysterectomy were excluded.

The collected data was processed thorough Statistical Package for the Social Sciences version 24 (SPSS 24, IBM, Armonk, NY, United States of America) for statistical calculations and analysis. Frequency distribution and descriptive statistics of all involved variables and the incidence were calculated. To find out association between infertility type and presence of fibroid, Chi-square test was applied and a p-value was calculated ( $p$-value less than 0.05 were considered significant).

\section{RESULTS}

Out of all 113 infertile women, primary infertility [71(62.8\%)] was more commonly reported as compared to secondary infertility [42(37.2\%)]. Table-I gives the detailed frequency distribution, range, standard deviation and mean values of the patient's age, duration of marriage, age at marriage and duration of last child birth. Patients come with various health issues and symptoms that are shown in Figure-1. Among the study subjects, $37 / 113(32.7 \%)$ had one child, 4/113(3.5\%) had two children and only $1 / 113(0.9 \%)$ had three children while rest of them $71 / 113(62.8 \%)$ reported to have had no child. Only $37(32.7 \%)$ out of 113 participants reported the presence of fibroids, while the rest of $76(67.3 \%)$ had no fibroids. The mean size of the fibroids was found to be $32.3568 \mathrm{~mm}$, with the smallest one being $7.30 \mathrm{~mm}$ and the largest $81.00 \mathrm{~mm}$. Most of the fibroids were of submucosal 11/37(9.7\%), sub-serosal 11/37(9.7\%) type and were commonly located in the anterior $14 / 37(12.4 \%)$ and posterior wall 14/37(12.4\%) of the uterus. A significant association ( $p$-value 0.010 ) was seen between existence of fibroid and the type of infertility. Cross Tabulation between existence of Fibroid and Type of Infertility is represented by Table-II. 


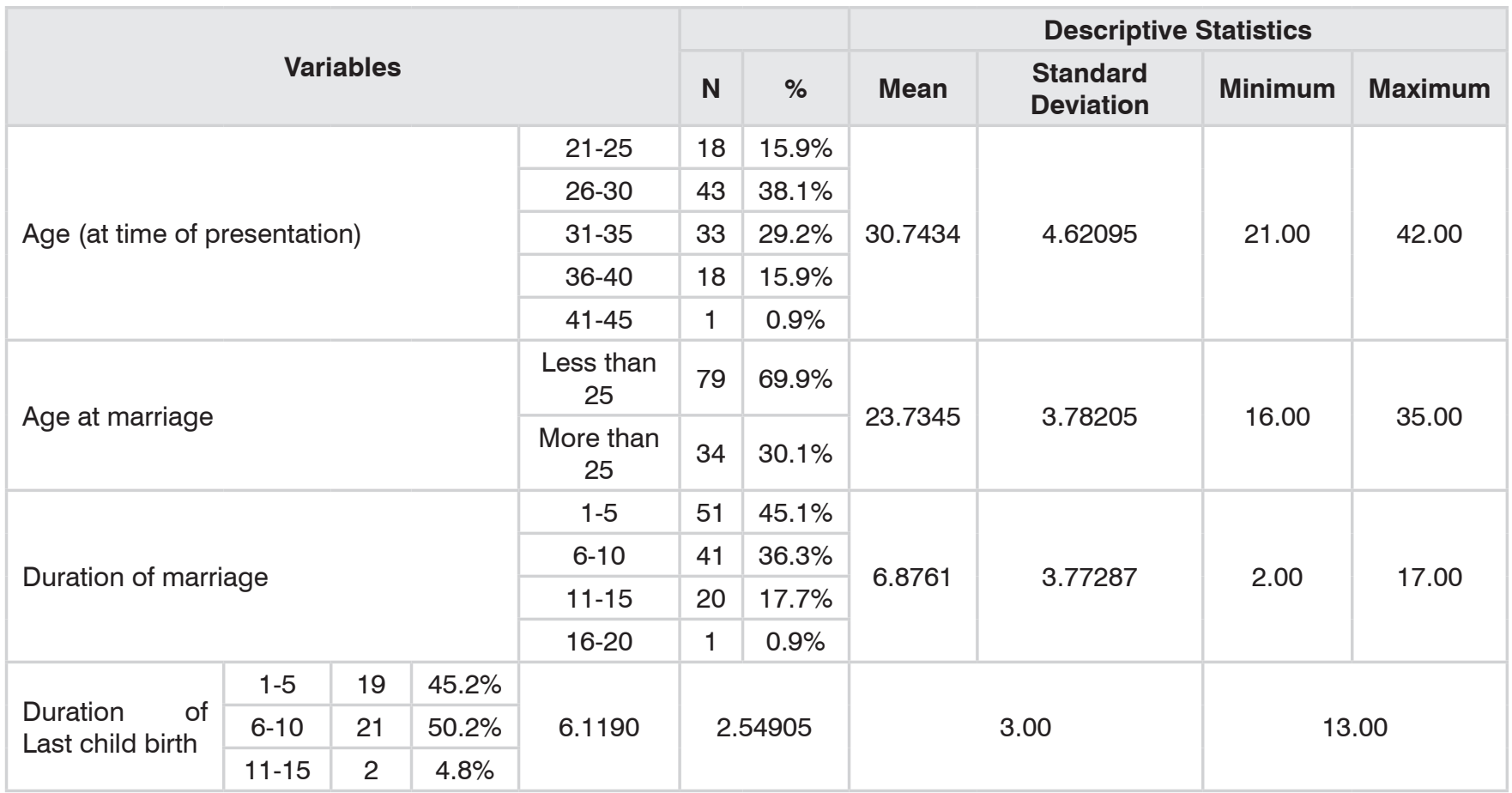

\section{Patient History}

25

\section{1}

20

15

14

10

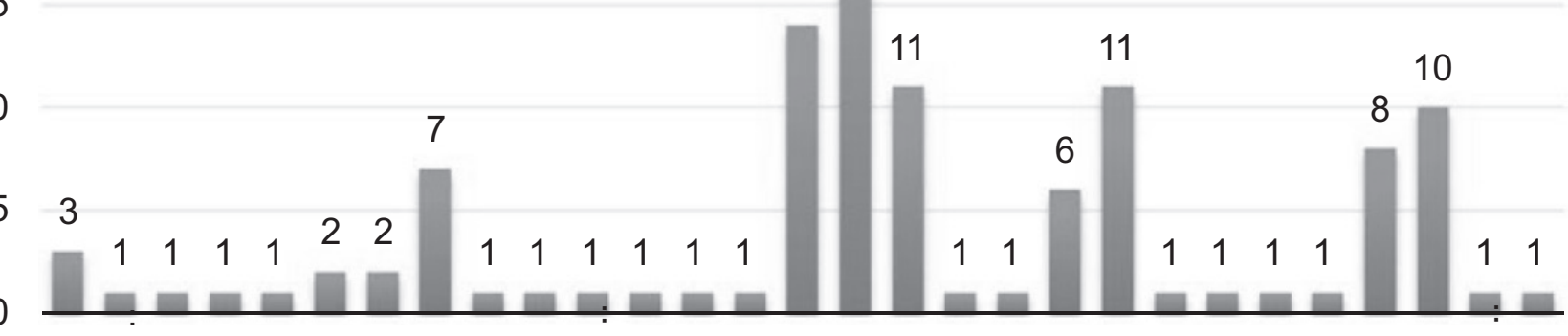

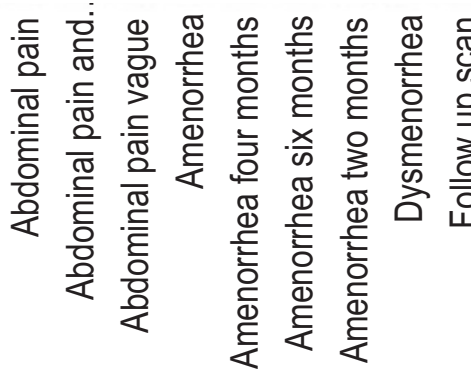

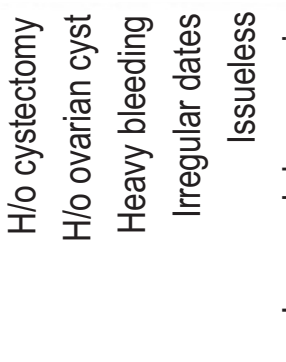

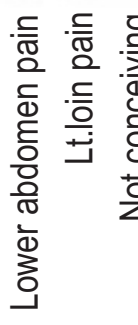

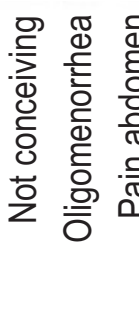

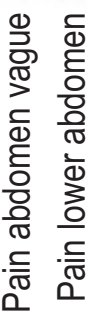

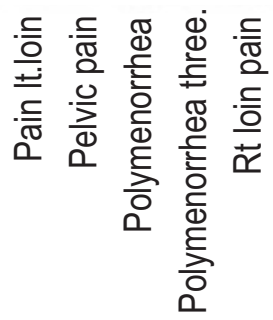

Patient History

Figure-1. Frequency distribution of the patient history. 


\begin{tabular}{|c|c|c|c|c|c|}
\hline \multirow{3}{*}{ Existence of Fibroids } & \multicolumn{4}{|c|}{ Types of Infertility (Primary or Secondary) } & \multirow{3}{*}{ Total } \\
\hline & \multicolumn{2}{|c|}{ Primary } & \multicolumn{2}{|c|}{ Secondary } & \\
\hline & $\mathbf{N}$ & $\%$ & $\mathbf{N}$ & $\%$ & \\
\hline No & 54 & $76.1 \%$ & 22 & $52.4 \%$ & 76 \\
\hline Yes & 17 & $23.9 \%$ & 20 & $47.6 \%$ & 37 \\
\hline Total & 71 & $100.0 \%$ & 42 & $100.0 \%$ & 113 \\
\hline
\end{tabular}

Table-II. Cross Tabulation between existence of Fibroid and Type of Infertility.

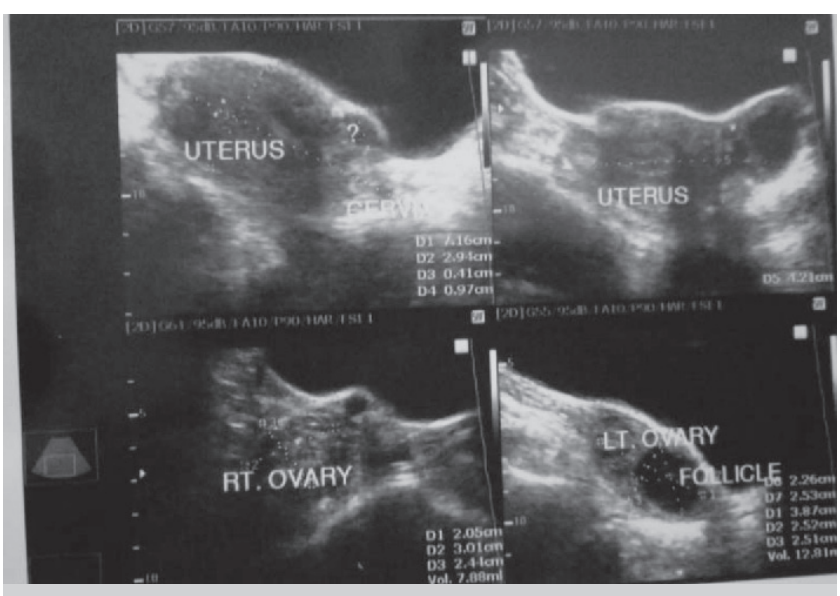

Figure-2. Single fibroid on the anterior wall of the uterus.

\section{DISCUSSION}

As this cross-sectional study was conducted to determine infertility's association with fibroid, so both the types of infertility were considered and similar to a study held in 2015 , a higher ratio of primary infertility as compared to secondary was noted. ${ }^{16}$ In accordance with geographical distribution, primary infertility was more commonly reported by Asian women as compared to African or Latin American women that commonly reported secondary infertility. ${ }^{17}$ There is the accompanying ascend in the mean age at which women present with infertility problem. In the present study the mean age at presentation was 30.7434 comparative to the mean age reported by Parveen et al. that is 28.4 years. ${ }^{18}$ Similarly a case control study on infertile women in Egypt showed a highest prevalence of females having no children followed by those having one and so on, was seemed to be supported by the results of this present study. ${ }^{19}$ On the other hand the duration of secondary infertility as seen in this study are very relative to a study held in Peshawar city in which 23/57 women had their last child birth less than 5 years back, 27/57 had duration between 6-10 years and only $7 / 57$ had duration of more than 10 years. ${ }^{20}$ The duration of marriage at which the patients presented with infertility complaint was maximum seen between $1-5$ years $(45.1 \%)$ followed by $6-10$ years duration $(36.3 \%)$ and same trend was noted in the study conducted by Siraj et al. ${ }^{21}$

For the patient history of health issues, irregular dates of menstruation was seen to be the most commonly reported in this current study whereas contrary to these results dysmenorrhea was most common complaint seen, $40 \%$ in primary and $30 \%$ in secondary infertile patients followed by irregular cycles and dyspareunia in a descriptive study conducted in Hyderabad for laparoscopic evaluation of infertility. ${ }^{22}$

A study conducted in 2017 at Bangalore India, showed an insignificant association, where only 3/35 subjects with primary infertility reported presence of fibroid while $1 / 15$ with secondary infertility did so, but this present study along with a study in 2012 at $\mathrm{MH}$ Rawalpindi, seemed to contradict these result by reporting a significant association. ${ }^{21}$ However, the general incidence of fibroid $37 / 113(32.7 \%$ ) in this study on the other hand, is somewhat similar as mentioned by Gupta.et al in 2008. ${ }^{23}$

Ultrasound is normally the underlying examination for looking at the female pelvis. The mean size of fibroids was $32.3565 \mathrm{~mm}$ and according to a study in 2018, the fibroid with the size more than $4 \mathrm{~cm}$ was seen to be a significant factor causing infertility. ${ }^{24}$ As for the location of Fibroid, the most commonly seen areas in this study were anterior and posterior walls and Peng et al. in 2012 seemed to support these outcomes. ${ }^{25}$ However the most common fibroid's type as supported by this and most others was intramural followed by sub-serosal and sub-mucosal. ${ }^{26}$ Ultrasound plays 
an important role to classify and assess uterine fibroids that help in management and further follow-up.

\section{CONCLUSION}

Uterine Fibroid prevalence according to this study was $32.7 \%$ and was seen to significantly associate with Infertility. Among the infertile women that reported the presence of fibroids, secondary infertility was seen to be more common as compared to primary infertility.

\section{Copyright@ 25 July, 2019.}

\section{REFERENCES}

1. Hakim A, Sultan M. Pakistan reproductive health and family planning survey (2000-01). Preliminary report. 2001.

2. Stevenson EL, Hershberger PE, Bergh PA. Evidencebased care for couples with infertility. Journal of Obstetric, Gynecologic \& Neonatal Nursing. 2016; 45(1):100-10.

3. McQuillan J, Greil AL, White L, Jacob MC. Frustrated fertility: Infertility and psychological distress among women. Journal of Marriage and Family. 2003; 65(4):1007-18.

4. Mascarenhas MN, Flaxman SR, Boerma T, Vanderpoel $S$, Stevens GA. National, regional, and global trends in infertility prevalence since 1990: A systematic analysis of $\mathbf{2 7 7}$ health surveys. PLoS medicine. 2012; 9(12):e1001356.

5. Shaheen R, Subhan F, Sultan S, Subhan K, Tahir F. Prevalence of infertility in a cross section of Pakistani population. Pakistan Journal of Zoology. 2010; 42(4).

6. Okolo S. Incidence, aetiology and epidemiology of uterine fibroids. Best practice \& research Clinical obstetrics \& gynaecology. 2008; 22(4):571-88.

7. Borgfeldt C, Andolf E. Transvaginal ultrasonographic findings in the uterus and the endometrium: Low prevalence of leiomyoma in a random sample of women age 25-40 years. Acta obstetricia et gynecologica Scandinavica. 2000; 79(3):202-7.

8. Lurie S, Piper I, Woliovitch I, Glezerman M. Age-related prevalence of sonographicaly confirmed uterine myomas. Journal of obstetrics and Gynaecology. 2005; 25(1):42-4.

9. FIBROIDS WCU. What are uterine fibroids? MRIGuided Focused Ultrasound Surgery. 2007:111.
10. Parker WH. Etiology, symptomatology, and diagnosis of uterine myomas. Fertility and sterility. 2007;87(4):72536.

11. Zimmermann A, Bernuit D, Gerlinger C, Schaefers M, Geppert K. Prevalence, symptoms and management of uterine fibroids: an international internet-based survey of 21,746 women. BMC women's health. 2012; 12(1):6.

12. Amoako A, Ola B. Fibroids and Infertility: Principles and Techniques of Management. Reproductive Surgery in Assisted Conception: Springer; 2015. p. 8596.

13. Eze J, UgwuA, Ohagwu C. The value of ultrasonography in the diagnosis of leiomyomas in Southeast Nigeria. Journal of Asian Scientific Research. 2013; 3(2):151.

14. Sarkodie BD, Botwe BO, Ofori EK. Uterine fibroid characteristics and sonographic pattern among Ghanaian females undergoing pelvic ultrasound scan: A study at 3-major centres. BMC women's health. 2016; 16(1):10.

15. American Institute of Ultrasound in Medicine, American College of Obstetricians and Gynecologists. AIUM practice guideline for the performance of ultrasound of the female pelvis. Journal of ultrasound in medicine: official journal of the American Institute of Ultrasound in Medicine. 2014 Jun;33(6):1122.

16. Al-Turki HA. Prevalence of primary and secondary infertility from tertiary center in eastern Saudi Arabia. Middle East Fertility Society Journal. 2015; 20(4):23740 .

17. Sharma S, Mittal S, Aggarwal P. Management of infertility in low resource countries. BJOG: An International Journal of Obstetrics \& Gynaecology. 2009; 116:77-83.

18. Parveen S, Khanam M. Role of combined diagnostic laparoscopy and simultaneous diagnostic hysteroscopy for evaluation of female subfertility factors. J Surg Pak (International). 2010; 15(1):44-7.

19. Mahran A, Abdelraheim AR, Eissa A, Gadelrab M. Does laparoscopy still has a role in modern fertility practice? International Journal of Reproductive Biomedicine. 2017; 15(12):787.

20. Akhtar R, Taj N, Mehnaz S, Furqan A, Khakwani M, Masood $\mathrm{H}$. Subfertile women; frequency of factors leading to tubal blockage evaluated by laparoscopy. Professional Medical Journal. 2017; 24(4). 
21. Siraj A, Choudry A, Naseer S, Humayun P, Khan $S$. Causes of infertility in females: evaluated by diagnostic laparoscopy at a tertiary care centre. Pakistan Armed Forces Medical Journal. 2015; 65(5):600-3.

22. Chimote A, Samal S, Hariharan C, Angik R. Laparoscopy and hysteroscopy in patients of infertility in a rural set up. International Journal of Reproduction, Contraception, Obstetrics and Gynecology. 2015; 4(2):323.

23. Gupta S, Jose J, Manyonda I. Clinical presentation of fibroids. Best practice \& research Clinical obstetrics \& gynaecology. 2008; 22(4):615-26.
24. Zepiridis LI, Grimbizis GF, Tarlatzis BC. Infertility and uterine fibroids. Best Practice \& Research Clinical Obstetrics \& Gynaecology. 2016; 34:66-73.

25. Peng S, Xiong Y, Li K, He M, Deng Y, Chen L, et al. Clinical utility of a microbubble-enhancing contrast ("SonoVue") in treatment of uterine fibroids with high intensity focused ultrasound: A retrospective study. European journal of radiology. 2012; 81(12):3832-8.

26. Sue W, Sarah S-B. Radiological appearances of uterine fibroids. The Indian journal of radiology \& imaging. 2009; 19(3):222.

\begin{tabular}{|c|c|c|c|}
\hline \multicolumn{4}{|c|}{ AUTHORSHIP AND CONTRIBUTION DECLARATION } \\
\hline Sr. \# & Author(s) Full Name & Contribution to the paper & Author(s) Signature \\
\hline 1 & Sana Amjad & Corresponding author & \\
\hline 2 & Hania Iqbal & Co-Author & \\
\hline 3 & Raham Bacha & SUpervisor + Reviewer & $x \rightarrow \infty$ \\
\hline 4 & Syed Amir Gilani & Reviewer (Final) & \\
\hline 5 & Muhammad Uzair & Co-supervisor & \\
\hline 6 & Sajid Shaheen Malik & Reviewer & $\mathscr{S}_{\mathrm{t}}$ \\
\hline 7 & Mehreen Fatima & Co-Author & -1/2e \\
\hline 8 & $\begin{array}{l}\text { S Muhammad Yousaf } \\
\text { Farooq }\end{array}$ & Reviewer & $\Leftrightarrow \%$ \\
\hline
\end{tabular}

